\title{
Priming Numbas for formative assessment in a first-year mathematics unit
}

\author{
Vivien Challis, Roger Cook and Pranit Anand \\ Queensland University of Technology
}

\begin{abstract}
This paper outlines an initiative that involved implementing 'Numbas' as a computer-based tool to support mathematics learning. 'Numbas' was implemented within the existing learning management system at Queensland University of Technology, where students engaged in formative assessment activities independently and were provided with automated feedback along the way. An initial evaluation was undertaken by learning designers using the 'Assessment Design Decisions Framework', and although more rigorous evaluation is underway, results indicate positive outcomes, and appropriate adjustment is likely to be made before rolling it out to other units within the School of Mathematical Sciences. This paper will be of interest to other educators looking for ways to embed independent computer-aided learning of mathematics.
\end{abstract}

Keywords: online assessment, e-assessment, formative assessment, mathematics

\section{Introduction}

The learning of mathematics in higher education involves students engaging in frequent problem-solving exercises to enable concept mastery and skill development. For many educators and students this is typically done within a face-to-face teaching environment, where educators are available to provide just-in-time feedback. In addition, there has been a trend over many years to use computer-based mathematical tools and to include authentic learning experiences to support student learning (Beevers et al., 1988). More recently, the COVID-19 pandemic required an online teaching and learning response sometimes referred to as "emergency remote teaching" (Hodges et al., 2020). This involved exploring digital options that would allow educators to create relevant learning activities and assessment tasks quickly and reliably. In the case of mathematics teaching, one option that has been effective is to incorporate online formative tasks to support independent learning and provide timely feedback (Graham, 2020; Greenhow, 2015). The School of Mathematical Sciences (SMS) at Queensland University of Technology (QUT) investigated the use of 'Numbas' as a computer-aided learning tool for undergraduate units. This was part of an ongoing teaching strategy to be incorporated into a new fully online undergraduate degree commencing in 2021, as well as to improve the online resources available to students during the COVID-19 emergency.

Numbas is a free and open-source e-assessment tool developed at Newcastle University by the School of Mathematics and Statistics (Newcastle University, 2018). Some of the main benefits of Numbas, as outlined by Perfect (2015) are: it is most suitable for formative assessment; it has been successfully deployed in undergraduate courses; it has client-side marking (but a server is still needed to store marks); it allows for the creation of questions using suitable mathematical notation and for students to input characters that are rendered mathematically; the interface is designed for inclusive access; it enables complex question creation that supports randomisation and automated marking; and it can be integrated with learning management systems such as Blackboard.

This paper investigates the use of Numbas in the first-year unit MXB105 Calculus and Differential Equations. An example quiz from MXB105 is shown in Figure 1 to highlight some of the question features: the question, an incorrect numeric answer, the expected answer, the score received, the question feedback or "advice", the number of questions in the quiz, and the total score. Numbas also provides teaching staff access to a dashboard that enables the analysis of quiz attempts by individual students (Figure 2) and of quiz statistics (Figure 3) that can inform further student support as well as possible changes to the design of questions. 


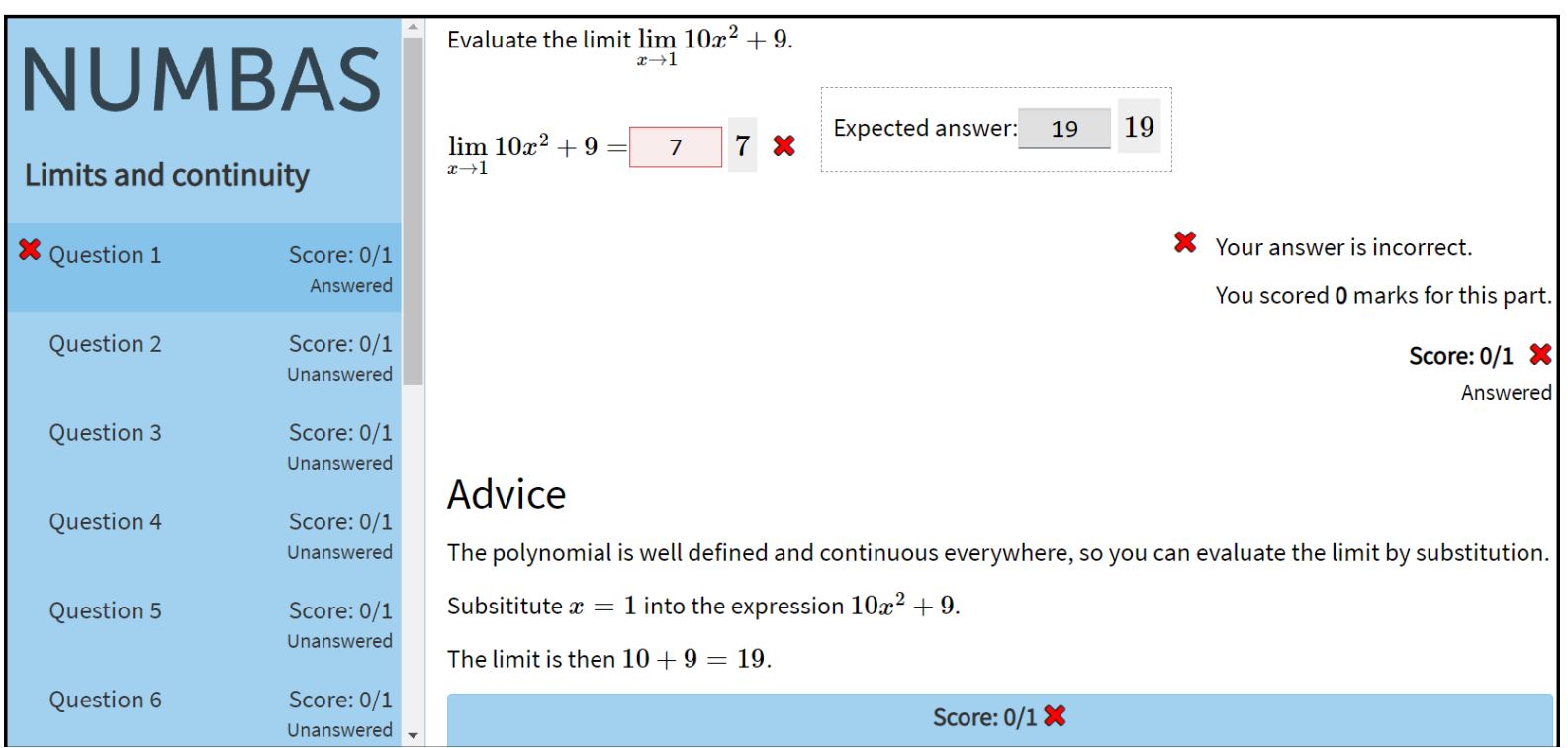

Figure 1. Quiz question example from MXB105

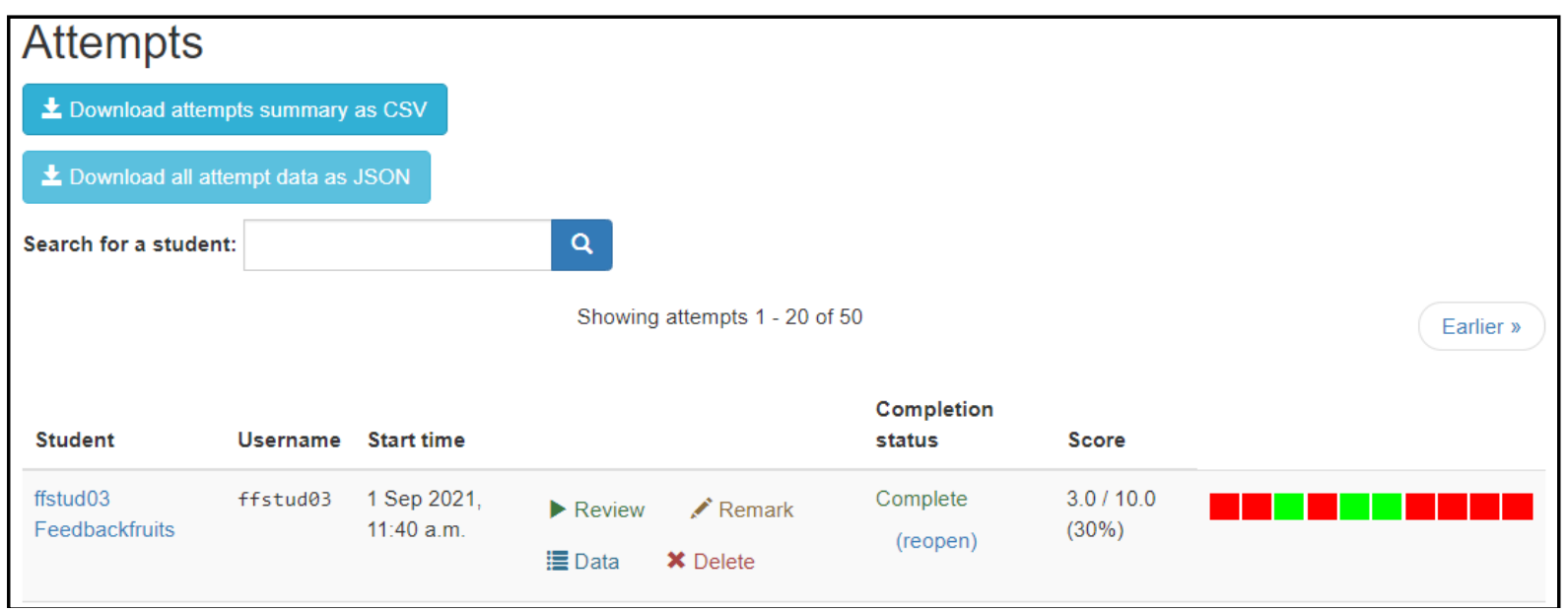

Figure 2. Numbas dashboard showing example individual attempt information from MXB105 quiz

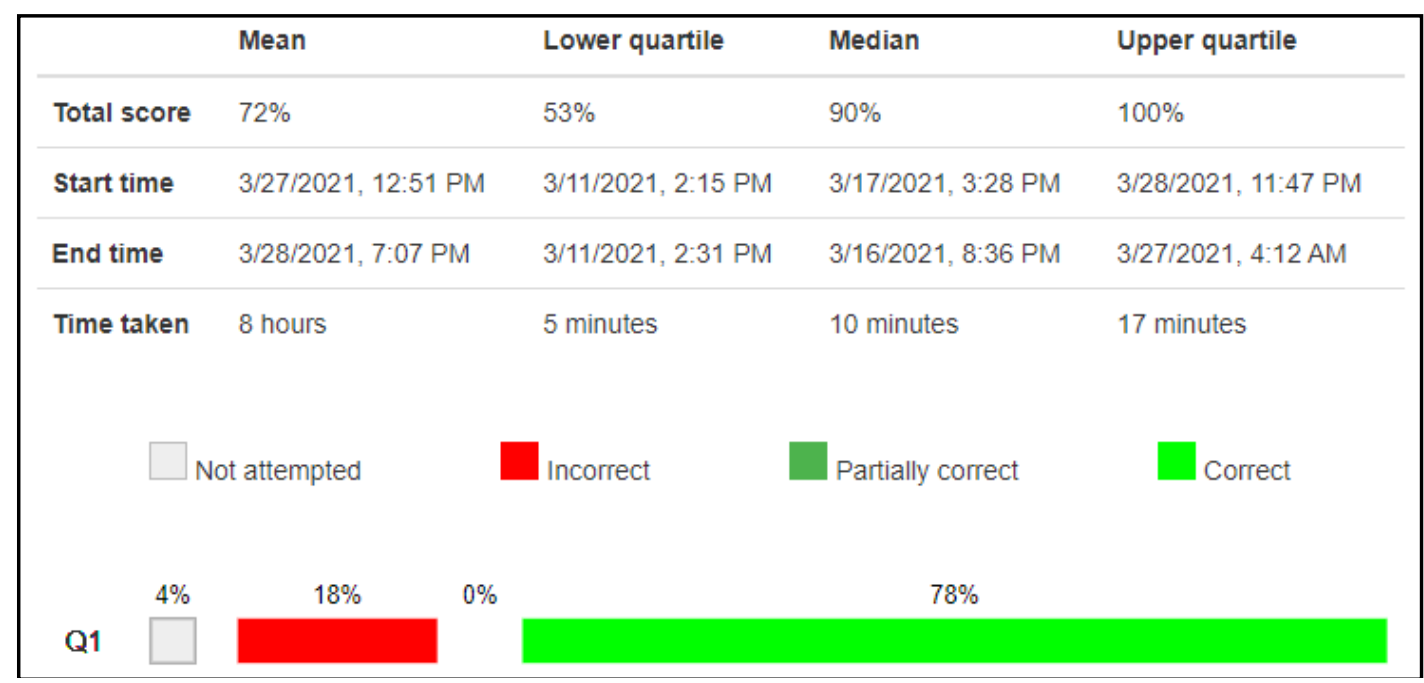

Figure 3. Numbas dashboard showing question statistics for MXB105 quiz 


\section{Methodology}

The aim of this study was to investigate the benefits and challenges encountered by an academic staff member (referred to in this paper as the "educator" and who is also a co-author) in piloting Numbas for formative assessment in a first-year undergraduate mathematics unit: MXB105 Calculus and Differential Equations. This is a preliminary study that will inform future directions for the potential adoption of Numbas within the School of Mathematical Sciences (SMS). In addition, it is intended that a more extensive evaluation of Numbas within both MXB105 and other units will occur at the end of 2021.

The educator taught MXB105 in Semester 2, 2020 with a cohort size of about 250 students and was a member of a redevelopment team to create an online version of the unit for delivery in Semester 1,2021. This first semester delivery included a full implementation of Numbas as a formative assessment tool that was integrated into Blackboard, the university's learning management system. The educator will also teach the unit in second semester, 2021, which will enable further refinement of this assessment approach as well as a more extensive and thorough evaluation.

Two learning designers (Roger and Anand) interviewed the educator using open-ended questions and completed a subsequent analysis based on the Assessment Design Decisions Framework (Dawson et al., 2014). The framework was used because it is accepted as a well-researched and practical approach for developing assessments in higher education. The framework highlights five insights and corresponding actions as shown in Table 1.

Table 1. The Assessment Design Decisions Framework (Dawson et al., 2014)

\begin{tabular}{ll}
\hline Insight & Action \\
\hline 1. Good assessment practice is about educators & $\begin{array}{l}\text { Identifying local exemplars both rewards innovators and } \\
\text { assists to normalise good practice. }\end{array}$ \\
\hline 2. Good assessment practice is supported & $\begin{array}{l}\text { Identify the supports and resources required for successful } \\
\text { assessment within a department, faculty, or institution. }\end{array}$ \\
\hline 3. Peer review improves assessment & $\begin{array}{l}\text { Leaders can implement changes to provide appropriate } \\
\text { amounts of formal and informal opportunity for peer } \\
\text { review. }\end{array}$ \\
\hline $\begin{array}{l}\text { 4. Effective assessment procedures balance } \\
\text { prescription and flexibility }\end{array}$ & $\begin{array}{l}\text { Feedback links between educators and those responsible } \\
\text { for policy/procedures can assist in ensuring the right } \\
\text { balance between quality regulation and responsiveness. }\end{array}$ \\
\hline $\begin{array}{l}\text { 5. Good assessment happens when L\&T } \\
\text { leaders in faculties/schools/departments are } \\
\text { engaged }\end{array}$ & $\begin{array}{l}\text { Value local L\&T leadership and identify ways for these } \\
\text { leaders to improve assessment in their faculty/department. }\end{array}$ \\
\hline
\end{tabular}

\section{Preliminary Findings and Discussion}

This section follows the Assessment Design Decisions Framework structure: Educator practice; Assessment support; Peer review; Assessment procedures; and Engagement with L\&T leadership.

\section{Educator focus}

There were a number of key reasons why the educator decided to implement Numbas as a formative assessment tool for Semester 1, 2021:

- The cohort in a first-year mathematics unit is typically very diverse in terms of previous mathematics skills and knowledge. It was important for students to be able to check their pre-requisite knowledge on a regular basis during the semester rather than only in a diagnostic quiz at the start of the semester (which happens in other units).

- In response to COVID-19 in 2020, all lectures at the university and some workshops were transitioned to an online format (either live or recorded). Instead of students passively consuming recordings, the educator was searching for a more active learning experience that students could attempt weekly or as part of their examination revision.

- The existing tools available did not enable the creation of relevant and reliable online assessment. SMS had been using WeBWork (The Mathematical Association of America, n.d.) for a number of years but in first 
semester 2020 experienced server load issues that compromised the reliability of the quizzes for summative assessment. The educator also evaluated the use of Blackboard quizzes but found the rendering of notation and creation of suitable questions was not acceptable.

- The Academic Lead (Learning and Teaching) for the SMS attended the E-Assessment in Mathematical Sciences conference in June 2020 (Newcastle University, 2021) and was impressed by Numbas as a possible tool for mathematics units. As a result, the educator carried out a small trial of Numbas in Semester 2, 2020 in MXB105 and students gave positive feedback about the quiz format and user-interface.

- In the second half of 2020, MXB105 was identified as a unit that would be part of a new online undergraduate Bachelor of Data Science degree, increasing the need for active learning experiences that students can attempt in their own time.

In summary, from the initial trial of using Numbas in the second semester of 2020, the educator identified these potential benefits: a range of useful mathematical question types could be created; quizzes could be auto-marked which helps to reduce the marking load for academics as well as enabling immediate and detailed feedback for students; client side marking meant that there would be no server issues (i.e., unlike WeBWork); and it could be integrated with Blackboard and its Grade Centre showing which students have attempted the quizzes.

\section{Assessment support}

The educator designed and developed Numbas quizzes that focused on students checking key concepts rather than attempting applied problems (i.e., the application of knowledge and skills was designed to occur in the weekly workshops). On average it was found that the time required to develop quizzes for one week of lecture material was approximately three hours and the estimated completion time for students was in the range of 10 to 30 minutes.

As for the design of the quiz questions, the educator relied on her own teaching experience of MXB105 in Semester 2, 2020 and reflected on what worked best in terms of examples and learning activities (e.g., polls, revision exercises) to identify relevant "conceptual stepping stones". The Numbas tool does allow for questions to be developed with other 'collaborators' and shared publicly for other users to use and/or customise further. However, the educator found the questions publicly available were not exactly applicable and were not using the same notation as in the MXB105 learning materials. This meant that it was more efficient to write her own questions from scratch. Although, she did find the Numbas documentation was very extensive and relatively easy to follow (refer to Newcastle University, 2019).

\section{Peer review}

Some peer support was provided to the educator during the implementation of the Numbas quizzes. The Academic Lead (Learning and Teaching) critiqued the user-interface, and the Mathematics Course Coordinator investigated the integration issues with Blackboard. However, the educator noted that "...this is very much just me going out on a limb here and trying something that I think will help the students and seeing how it goes".

The educator stated that SMS does have several ways for teaching teams to share ideas about curriculum, learning materials and activities, and assessment but how a unit is delivered is often the sole responsibility of the individual unit coordinator(s).

\section{Assessment procedures}

Overall, the educator did not refer to any assessment policy or procedures during the development of the quizzes. She noted that she was relatively new to the university and that there was a range of opinions within the school about how assessment should be carried out with some staff adhering to guidelines while others were looking at ways to be more innovative and responsive to student needs. She did make the positive comment that "...in mathematics we see ourselves as a school that does work hard for our teaching and ... generally staff do put in a lot of effort". 


\section{Engagement with L\&T leadership}

The educator's engagement with and support from senior leaders was crucial in enabling the use of Numbas to be ready for Semester 1, 2021:

- As noted above, the Academic Lead (Learning and Teaching) could see clear benefits for staff and students using Numbas and also consulted with the Head of School about this.

- The Mathematics Course Coordinator, who has familiarity with IT systems, set up a sandpit environment in Amazon Web Services to successfully test the use of Numbas with Moodle, a free learning management system.

- The faculty's Assistant Dean (Learning and Teaching) liaised with the university's IT department to ensure that the Blackboard integration occurred in a timely and reliable manner.

One thing that the educator was very mindful of was ongoing sustainability regarding how questions are created and shared amongst teaching teams; how staff are to be trained in the use of Numbas; and what oversight is required by the school in terms of effectiveness and suitability.

\section{Next steps}

During the interview, the educator also provided commentary about how she intends to use Numbas in the future as well as considerations that could be made by the school. As noted above, the educator will be the unit coordinator in MXB105 in Semester 2, 2021 with an expected cohort size of 200-250 students. She intends to provide a rationale to students (and reinforce this each week) about the importance of attempting the Numbas quizzes. The use of Numbas will be further evaluated to answer questions such as these:

- Were the questions useful and pitched at the right level?

- Was the feedback useful in the quizzes?

- To what extent did students attempt the quizzes?

- What question designs and types are most suited for concept checking?

- How did their use of Numbas correlate with their final grades?

- When do students actually complete the quizzes (e.g., weekly; or at the end of the semester to revise for the exam)?

In terms of the adoption of Numbas across the school, the educator recommended the following:

- Question design needs to be further explored. It is straightforward to create simple questions, but more complex options are available (e.g., adaptive marking, variable randomisation, and the use of question pools).

- It may be advisable for the university to set up its own Numbas editor which may facilitate the shared editing and deployment of quizzes.

- Numbas may be suitable for low stakes summative assessment including on-campus exams in a computer lab. However, one of the drawbacks of Numbas having client-side marking is that students can access answers via a question's HTML code. Newcastle University has addressed this by creating their own custom app for students to access assessment quizzes. They also suggest options for locking down browsers and only allowing access from such secure browsers. These options need to be explored if the school wishes to use Numbas more broadly for summative assessment.

\section{Summary}

In summary, this investigation showed that even though the development of a new online undergraduate course and the remote emergency response to COVID-19 were catalysts for rapid change, the main driver for change in the implementation of Numbas was the educator. Her commitment to student learning, ability to reflect on her teaching practice and readiness to devote a substantial amount of time to this work was the driver for the initial success. Now that this groundwork has occurred, broader support from peers, the school and the university is required to better understand and share relevant pedagogical and technical requirements which will also need to be underpinned by more extensive and rigorous evaluation. Furthermore, as noted by Ní Fhloinn and Carr (2017), students need to be aware of how simpler formative assessment tasks in Numbas align with the completion of more complex, high-stakes and time-intensive summative assessment tasks.

The use of computer-based learning of mathematics is increasingly being demonstrated as an authentic way for 
students to learn mathematics. However, due to traditional practices and educator norms about teaching and learning mathematics, as a discipline it can be challenging to adapt contemporary computer-based tools. As this initial study has shown it is possible to meaningfully embed a computer-based tool to help students engage in formative problem-solving exercises and get timely feedback along the way. However, constraints related to "infrastructure, support, educator and student skills, and limited time" need to be considered and dealt with effectively (Bennett et al., 2017, p. 673).

As an educative tool, Numbas provides opportunities for higher education educators of mathematics to give students opportunities for independent study and feedback (Carroll et al., 2017; Casey \& Crowley, 2019). Furthermore, Numbas is compatible with most common learning management systems, meaning that educators can get real-time data about student engagement, and an indication about their learning behaviours and progress.

\section{References}

Bennett, S., Dawson, P., Bearman, M., Molloy, E., \& Boud, D. (2017). How technology shapes assessment design: Findings from a study of university teachers. British Journal of Educational Technology, 48(2), 672682. https://doi.org/10.1111/bjet.12439

Beevers, C., Cherry, B. S., Clark, D. E., Foster, M., McGuire, G., \& Renshaw, J. (1988). The CALM before the storm! CAL in university mathematics. Computers and Education, 12(1), 43-47. https://doi.org/10.1016/0360-1315(88)90053-X

Carroll, T., Casey, D., Crowley, J., Mulchrone, K., \& Ní Shé, Á. (2017). Numbas as an engagement tool for first-year Business Studies students. MSOR Connections (Online), 15(2), 42-50. https://doi.org/10.21100/msor.v15i2.410

Dawson, P., Bearman, M., Joughin, M., Hall, M., Bennett, S., Molloy, E. \& Boud, D. (2014). Five insights for improving university assessment practices. http://www.assessmentdecisions.org/five-insights-for-improvinguniversity-assessment-practices/

Graham, C. (2020). Assessment of computing in the mathematics curriculum using Numbas. MSOR Connections (Online), 18(2), 49-58. https://doi.org/10.21100/msor.v18i2.1098

Greenhow, M. (2015). Effective computer-aided assessment of mathematics; principles, practice and results. Teaching Mathematics and Its Applications, 34(3), 117-137. https://doi.org/10.1093/teamat/hrv012

Hodges, C., Moore, S., Lockee, B., Trust, T. \& Bond, A. (2020). The Difference Between Emergency Remote Teaching and Online Learning. https://er.educause.edu/articles/2020/3/the-difference-between-emergencyremote-teaching-and-online-learning

Newcastle University. (2018). Numbas: really versatile maths e-assessment. https://www.numbas.org.uk/

Newcastle University. (2019). Numbas Documentation. https://docs.numbas.org.uk/en/latest/index.html

Newcastle University. (2021). E-Assessment in Mathematical Sciences. https://eams.ncl.ac.uk/

Ní Fhloinn, E., \& Carr, M. (2017). Formative assessment in mathematics for engineering students. European Journal of Engineering Education, 42(4), 458-470. https://doi.org/10.1080/03043797.2017.1289500

Perfect, C. (2015). A demonstration of Numbas, an assessment system for mathematical disciplines. https://www.numbas.org.uk/wp-content/uploads/2015/07/caa2015 numbas.pdf

The Mathematical Association of America. (n.d.). What is WeBWork? https://webwork.maa.org/intro.html

Challis, V., Cook, R. \& Anand, P. (2021). Priming Numbas for formative assessment in a first-year mathematics unit. In Gregory, S., Warburton, S., \& Schier, M. (Eds.), Back to the Future-ASCILITE '21.

Proceedings ASCILITE 2021 in Armidale (pp. 313-318). https://doi.org/10.14742/ascilite2021.0145

Note: All published papers are refereed, having undergone a double-blind peer-review process.

The author(s) assign a Creative Commons by attribution licence enabling others to distribute, remix, tweak, and build upon their work, even commercially, as long as credit is given to the author(s) for the original creation.

(C) Challis, V., Cook, R. \& Anand, P. 2021 